\title{
Age-Associated Alterations of Hippocampal Place Cells Are Subregion Specific
}

\author{
Iain A. Wilson, ${ }^{1}$ Sami Ikonen, ${ }^{1}$ Michela Gallagher, ${ }^{2}$ Howard Eichenbaum, ${ }^{3}$ and Heikki Tanila ${ }^{1,4}$ \\ ${ }^{1}$ Department of Neuroscience and Neurology, University of Kuopio, Kuopio 70211, Finland, ${ }^{2}$ Department of Psychological and Brain Sciences, Johns \\ Hopkins University, Baltimore, Maryland 21218, ${ }^{3}$ Department of Psychology, Boston University, Boston, Massachusetts 02215, and ${ }^{4}$ Department of \\ Neurology, Kuopio University Hospital, Kuopio 70211, Finland
}

\begin{abstract}
Aging is associated with spatial memory impairments and with deficient encoding of information by the hippocampus. In young adult rats, recent studies on the firing properties of hippocampal neurons have emphasized the importance of the CA3 subregion in the rapid encoding of new spatial information. Here, we compared the spatial firing patterns of CA1 and CA3 neurons in aged memory-impaired rats with those of young rats as they explored familiar and novel environments. We found that CA1 place cells in aged and young rats had similar firing characteristics in the familiar and novel environments. In contrast, aged CA3 place cells had higher firing rates in general and failed to change their firing rates and place fields as much as CA3 cells of young rats when the rats were introduced to a novel environment. Thus, aged CA3 cells failed to rapidly encode new spatial information compared with young CA3 cells. These data suggest an important and selective contribution of CA3 dysfunction to age-related memory impairment.
\end{abstract}

Key words: aging; age-associated cognitive impairment; CA1; CA3; hippocampus; place cells; spatial memory

\section{Introduction}

Aging is associated with spatial learning impairment (Barnes, 1979; Gallagher et al., 1993), and this reflection of cognitive decline has been attributed to deficient encoding of information by hippocampal neurons. To analyze how spatial information is processed, researchers have recorded hippocampal place cells, pyramidal neurons that fire strongly when a freely behaving rat occupies particular locations in an environment. Spatial coding by place cells is altered in aged rats in a number of experimental settings (for review, see Rosenzweig and Barnes, 2003), and such abnormalities correlate with the degree of spatial learning impairment (Wilson et al., 2003).

Much research has shown that the hippocampus of young animals is critical for navigation using external landmarks (Morris et al., 1982), but, until recently, experimental evidence for the specific contribution of each hippocampal subregion has remained elusive. Indeed, because of many similarities in the characteristics of CA1 and CA3 place cells, data have often been pooled across those subregions to increase statistical power (Bostock et al., 1991; Tanila et al., 1997b; Oler and Markus, 2000; Save et al., 2000; Wilson et al., 2003). However, recent experiments in young animals have identified unique characteristics of information coding by CA1 and CA3 cells, indicating a possible basis for distinct contributions of each hippocampal subregion to mem-

Received May 2, 2005; revised June 7, 2005; accepted June 7, 2005.

This work was supported by National Institute on Aging Grant AG09973, Academy of Finland Grant 46000, by the Northern Savonia Cultural Foundation, and by the Research and Science Foundation of Farmos. We thank Dr. Matthew Shapiro for much of the analysis software.

Correspondence should be addressed to lain A. Wilson, Department of Neuroscience and Neurology, University of Kuopio, P.0. Box 1627 (Harjulantie 1), Kuopio 70211, Finland. E-mail: lain.Wilson@uku.fi.

DOI:10.1523/JNEUROSCI.1744-05.2005

Copyright $\odot 2005$ Society for Neuroscience $\quad$ 0270-6474/05/256877-10\$15.00/0 ory (for review, see Guzowski et al., 2004). The CA3 subregion exhibits characteristics particularly suited for rapid learning of environment-specific features (Nakazawa et al., 2003); specifically, CA3 pyramidal cells show an abrupt all-or-none change in their encoding in response to modifications of familiar environments or exposure to novel environments (Lee et al., 2004a; Leutgeb et al., 2004; Vazdarjanova and Guzowski, 2004). In contrast, CA1 pyramidal cells respond more gradually to graded changes in the environment (Leutgeb et al., 2004; Vazdarjanova and Guzowski, 2004), suggesting that the CA1 subregion serves to compare outputs of CA3 with direct inputs from entorhinal cortex.

Neurobiological investigations on aging have repeatedly stressed regional specificity of changes within the hippocampus, affecting synaptic connections, physiology, and plasticity (Barnes, 1994; Rapp et al., 1999; Smith et al., 2000), but little is known about possible differences in the effects of aging on place cell firing patterns in CA1 and CA3 subregions. Previous reports, in which neurons from each subregion were pooled for analyses, showed that place cells of aged rats fail to rapidly encode new information (Tanila et al., 1997a; Oler and Markus, 2000; Wilson et al., 2003, 2004). By analyzing each subregion separately from data of four novel-environment experiments (Tanila et al., 1997b; Wilson et al., 2003, 2004, 2005), the current study examines how CA1 and CA3 place cells of young and aged rats may differentially encode a highly familiar environment and a new visually distinctive environment. Based on recent evidence implicating the CA3 subregion in the rapid encoding of new information (Nakazawa et al., 2003; Lee et al., 2004a; Leutgeb et al., 2004), we hypothesized that age-related changes in information processing would be particularly evident in the CA3 subregion. 


\section{Materials and Methods}

Subjects and surgery

The subjects were 18 young (6-8 months of age) and 17 aged (25-27 months of age) male Long-Evans rats. The rats were prescreened for spatial memory performance in the Morris water maze task at Johns Hopkins University, as described in our previous reports (Gallagher et al., 1993; Wilson et al., 2003). Electrode implantations and recordings were then made at the University of Kuopio, Finland (14 young and 12 aged rats) or at the State University of New York at Stony Brook (Stony Brook, NY) (four young and five aged rats). Each rat was implanted with two to four movable tetrodes aimed to the dorsal hippocampus (anteroposterior, $-3.3 \mathrm{~mm}$; mediolateral, $+2.0 \mathrm{~mm}$; dorsoventral, $-2.2 \mathrm{~mm}$ from the dura). The recording electrodes were advanced to the pyramidal cell layers. After finding well isolated neurons, they were recorded while the rats explored the familiar environment followed by one of four new environments. The first well isolated pyramidal cells were from CAl cells for 18 rats and from anterior CA3 cells for seven rats. Each exposure to a new environment took place on separate days, and, if isolation of the neurons was lost before completion of all recordings, the electrodes were again advanced to new cells. Some electrodes were advanced down to hilar CA3 for recordings (six rats) (see the histology from Fig. 1). Recordings from CA1 and CA3 subregions were not simultaneous for either young or aged rats.

In addition to the tetrodes, bipolar stimulation electrodes were implanted in the lateral hypothalamus to deliver rewarding brain stimulation. The stimulus current was adjusted to the minimum level that kept each rat constantly moving. Additional details of the recording and stimulation techniques are found in Ikonen et al. (2002). All animal experiments were conducted in accordance with guidelines of the Council of Europe and the U.S. National Institutes of Health.

\section{Behavioral protocols}

Water maze. The rats were trained on a spatial version of the Morris water maze task, designed to test hippocampal learning abilities, and on a cued version of the water maze to test visual acuity. Details of these tests can be found in Wilson et al. (2003).

Place cell recordings. All rats from the Kuopio experiments were trained to search for randomly distributed loci at which rewarding brain stimulation was delivered in a cylindrical environment (diameter, $70 \mathrm{~cm}$; height, $50 \mathrm{~cm}$ ) with three distinct two-dimensional patterns attached to the cylinder wall serving as landmark cues. After several weeks of screening for cells, place cells were recorded from this highly familiar cylinder and one of three novel environments, each on a separate day. Each arena was located in the same room location on a black plastic table. The rat explored the familiar cylinder for $7 \mathrm{~min}$ and was then placed in a holding bucket while the arena was changed and the floor cleaned. The rat was gently spun in the bucket for mild disorientation before being placed in the novel arena for the $7 \mathrm{~min}$ trial.

Novel environment 1 was a black hexagon with three novel landmarks. See the top row of Figure 2 for illustration and Wilson et al. (2004) for details. Novel environment 2 was a brown square, which bore the original three landmarks from the cylinder in a $90^{\circ}$ rotated position. See the top row of Figure 4 for illustration and Wilson et al. (2003) for details. Novel environment 3 was a smaller rectangular cardboard box with three novel landmarks. Novel environment 3 is not illustrated in the figures, but details can be found in Wilson et al. (2005). After the novel environment, the rats were returned to the familiar environment to provide a control comparison for the change to the novel environment. To sample more cells and to allow the possibility to test the effects of additional exposures to the novel environments, eight young rats and 12 aged rats were recorded twice in novel environments 1 and 2. To increase the sample size, these two sessions were pooled unless the effect of repetitive exposure was specifically tested.

The rats from the Stony Brook experiments (novel environment 4) were treated in much the same way, except that the familiar environment was a plus maze with rewards given at the end of each arm. The maze had different odors and textures on the floor of each arm and was surrounded by black curtains with prominent hanging visual cues. For the novel environment, the surrounding black curtains were opened, new visual
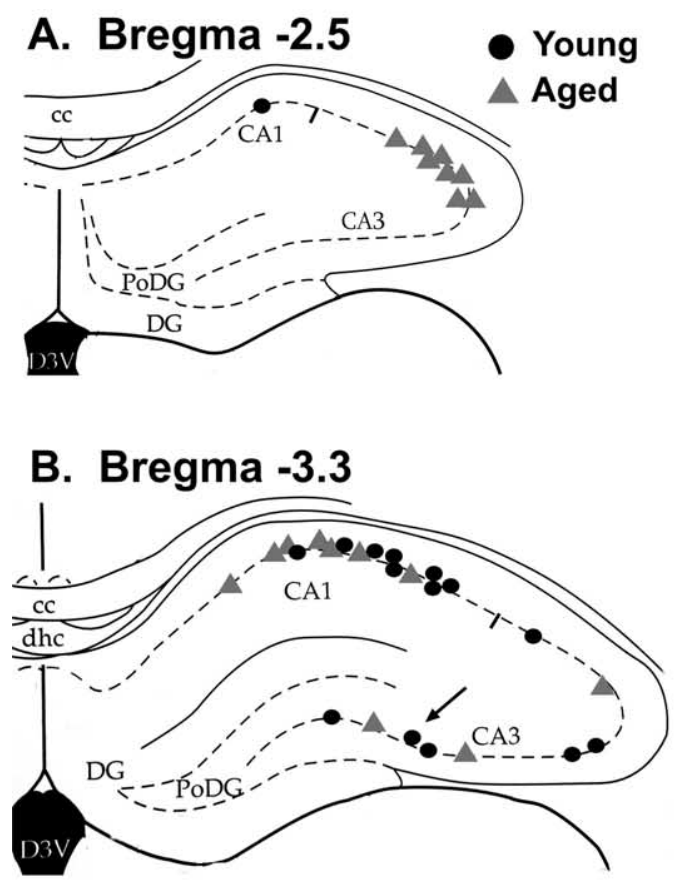

\section{Bregma -3.8}

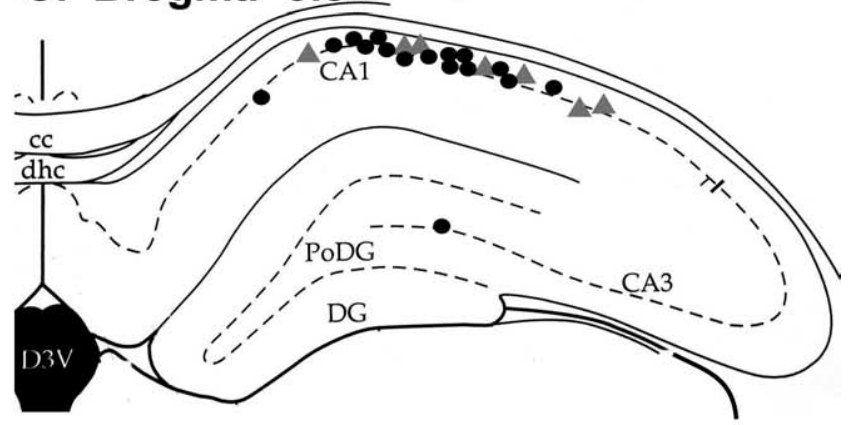

D. Example from histology

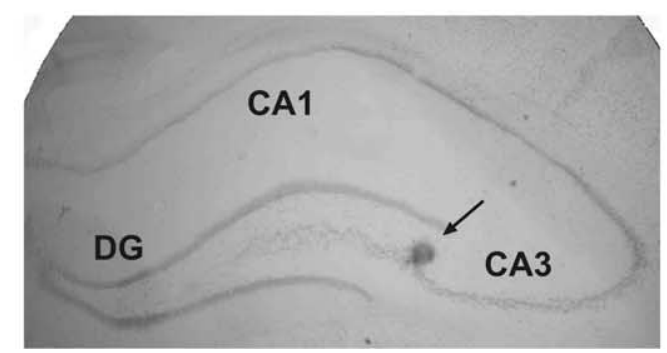

Figure 1. Locations of the recording sites as determined by histology. Each site in which place cells were recorded with tetrodes is marked for young rats (black circles) and aged rats (gray triangles) in the hippocampus [adapted from Paxinos and Watson (1998)]. A, Recordings from bregma $-2.5 \mathrm{~mm}$. $\boldsymbol{B}$, Recordings from bregma $-3.3 \mathrm{~mm}$. The arrow marks the site of the example section. $\boldsymbol{C}$, Recordings from bregma $-3.8 \mathrm{~mm}$. $\boldsymbol{D}$, An actual example of a histological section. The arrow marks the tetrode location that was marked with the Prussian blue reaction. cc, Corpus callosum; PoDG, polymorphic region of the dentate gyrus; DG, dentate gyrus; D3V, dorsal third ventricle; dhc, dorsal hippocampal commissure.

landmarks were hung, and the plus maze floor odors were removed. Before being placed in the novel environment, rats were disoriented by being carried in a closed bucket on a brief tour of laboratory rooms. For additional details, see Tanila et al. (1997b), and, for illustration, see the top row of Figure 3. 

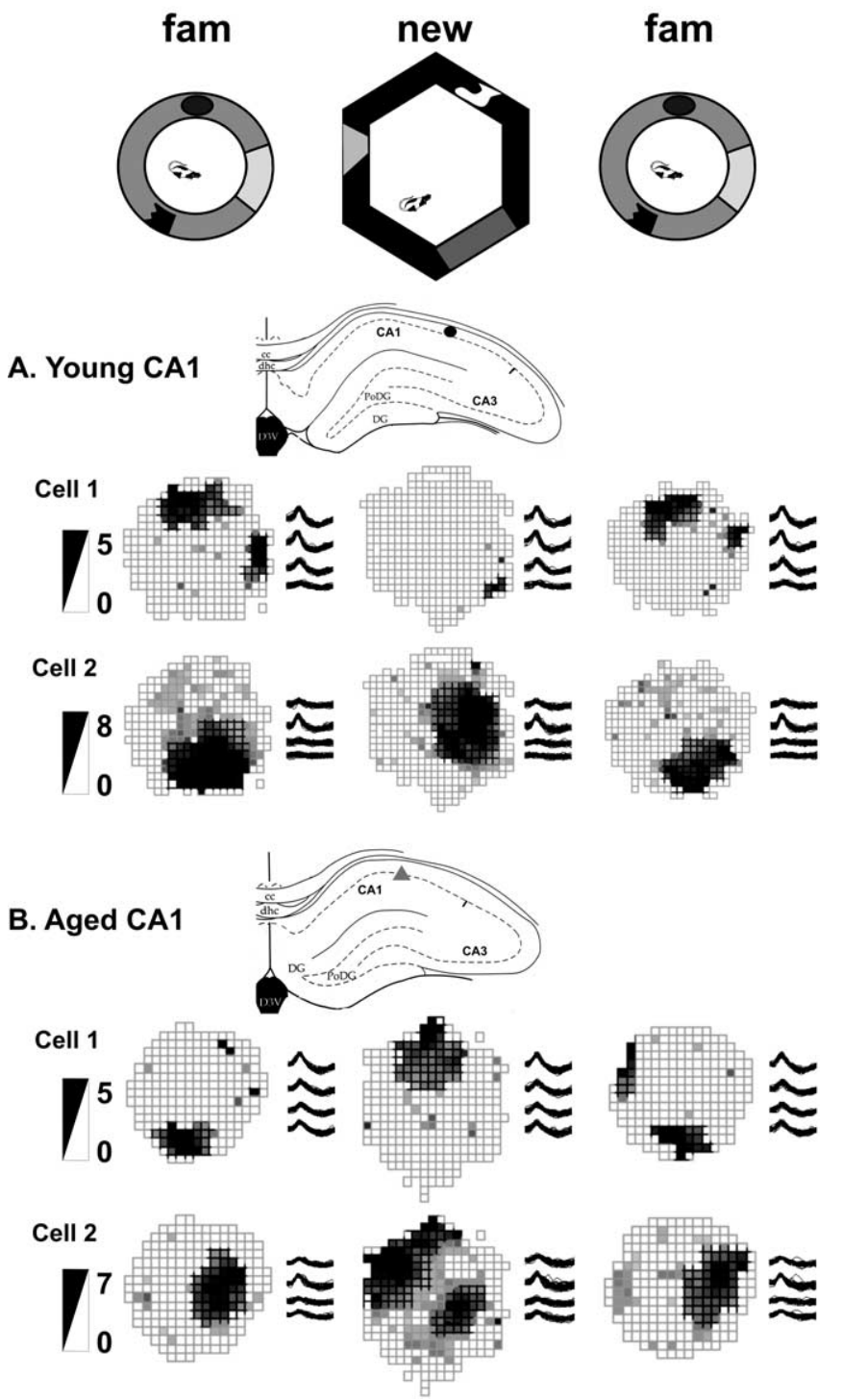

Figure 2. Examples of young $(\boldsymbol{A})$ and aged $(\boldsymbol{B})$ CA1 place fields. The top row shows the experimental setup with the familiar (fam) environment and novel environment 1. The recording sites, the place fields, the tetrode waveforms, and the firing rate scale (in spikes per second) of two simultaneously recorded cells from each rat are shown. Note that the CA1 cells of both groups predominantly created new spatial representations, although firing rates (young cell 2) and even some subfields (aged cell 2) were often similar between the environments. cc, Corpus callosum; PoDG, polymorphic region of the dentate gyrus; DG, dentate gyrus; D3V, dorsal third ventricle; dhc, dorsal hippocampal commissure.

\section{Histology}

At the end of the study, the rats were deeply anesthetized and the recording sites were marked by passing anodal current $(30 \mu \mathrm{A}, 5 \mathrm{~s})$ through the electrodes. The animals were perfused with buffered $4 \%$ formalin, and the brains were cut into $50-\mu \mathrm{m}$-thick coronal sections. The locations of the electrode tips were confirmed by Prussian blue reaction, as described previously (Tanila et al., 1997a). See Figure $1 D$ for an example of the histology.

\section{Spatial firing analysis}

The recordings were made with Enhanced Discovery software, and cells were isolated off-line by clusters defined with waveform parameters using Autocut software (both from DataWave Technologies, Longmont, $\mathrm{CO})$. To focus our analyses on pyramidal neurons of the CA1 and CA3 subregions, we limited our analyses to cells that showed complex spikes (to eliminate interneurons) and that had spike widths measured as the time difference between the maximum and minimum amplitudes of
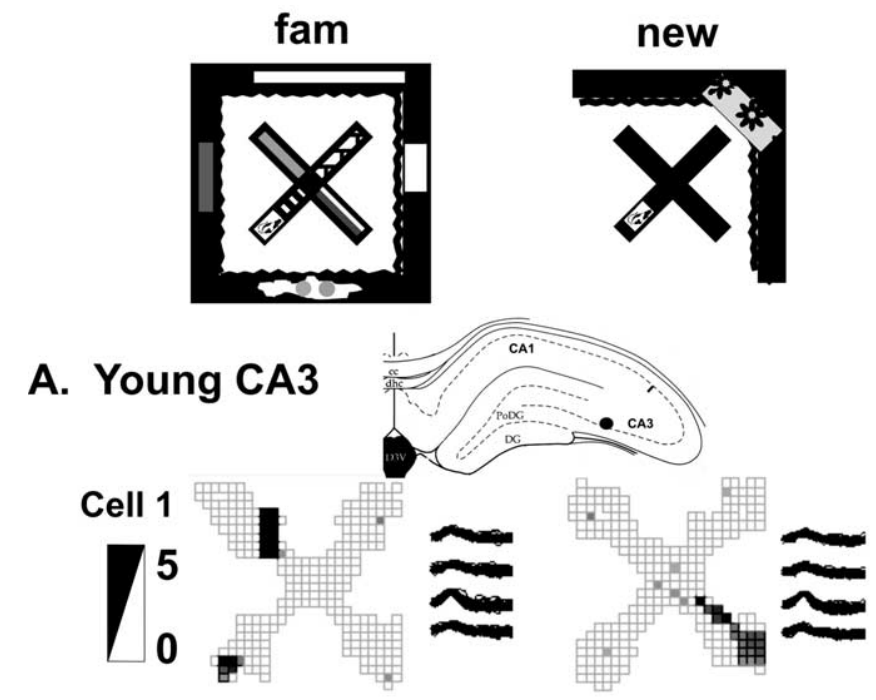

\section{Cell 2
5
0}
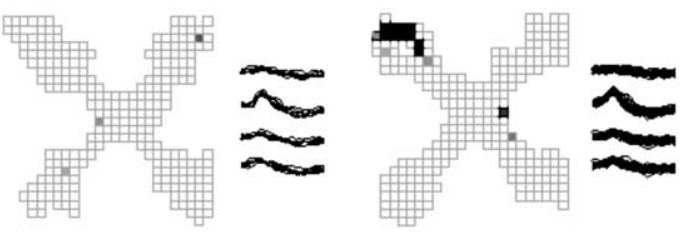

\section{B. Aged CA3}
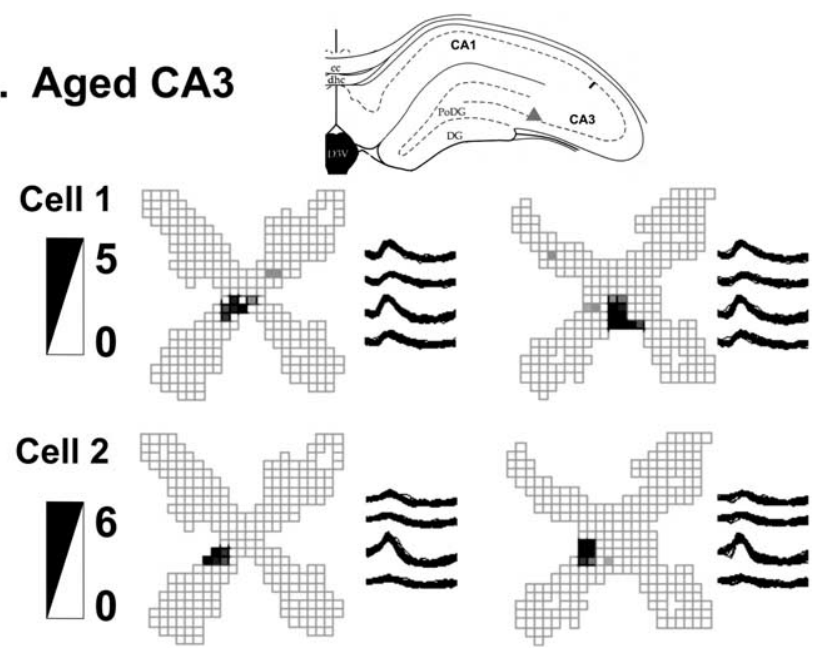

Figure 3. Examples of young $(\boldsymbol{A})$ and aged $(\boldsymbol{B})$ CA3 place fields. The top row depicts the experimental setup with the familiar (fam) environment and novel environment 4 . The recording sites, the place fields, the tetrode waveforms, and the firing rate scale (in spikes per second) of two simultaneously recorded cells from each rat are shown. Note that young CA3 cells created new spatial representations, and often some were active in only one environment (young cell 2). In contrast, the aged $C A 3$ cells used similar place field representations for both environments and scarcely changed their firing rates. cc, Corpus callosum; PoDG, polymorphic region of the dentate gyrus; DG, dentate gyrus; D3V, dorsal third ventricle; dhc, dorsal hippocampal commissure.

$>380 \mu$ s [beyond the range of interneurons and dentate gyrus granule cells (Jung and McNaughton, 1993)]. Only place cells were included in the study and, to qualify, the pyramidal cells had to have clear place fields in at least one environment and show clear amplitude differences between the four tetrode channels (indicating good isolation). Place fields were defined as a set of at least six adjacent pixels with firing rates $>0.5$ $\mathrm{Hz}$ and two times above the overall mean firing rate of the cell.

To compare the properties of place cells between groups within environments, we examined three aspects of the firing rates and the spatial selectivity of the firing. First, we measured the mean overall firing rates calculated for periods when the rat was moving at least $2 \mathrm{~cm} / \mathrm{s}$. This speed filter minimized contamination of the location-specific firing with spikes 
that occur during sharp-wave activity (Chrobak and Buzsaki, 1998). All measures were filtered for movement. Second, we examined the maximum firing rate reached for each cell and the area of significant firing (pixels with a firing rate of $>1 \mathrm{~Hz}$ ). Third, we assessed spatial selectivity of the firing by measuring the spatial information content, a measure that examines how well the action potentials of a cell predict the animal's location (Skaggs et al., 1993; Markus et al., 1994). The formula used was the following: spatial information content $=\Sigma P_{i}\left(f r_{i} / f r\right) \log _{2}\left(f r_{i} / f r\right)$, where $i$ is the pixel number, $P_{i}$ is the probability for occupancy of pixel $i, f r_{\mathrm{i}}$ is the mean firing rate for bin $i$, and $f r$ is the overall firing rate.

To measure the extent to which a spatial representation changed between manipulations of the environment, we measured both the raw firing rate change (accounting for direction) and the magnitude of firing rate change (independent of direction) across environments. The raw firing rate change was calculated as follows: $\left[\left(f r_{1}-f r_{2}\right) /\left(f r_{1}+f r_{2}\right)\right] \times$ $100 \%$, such that $f r_{1}$ is the mean overall firing rate in the familiar environment, and $f r_{2}$ is the mean overall firing rate in the new environment.

The magnitude of firing rate change was calculated as follows: ABS $\left[\left(f r_{1}-f r_{2}\right) /\left(f r_{1}+f r_{2}\right)\right] \times 100 \%$, such that ABS is absolute value. The absolute maximum firing rate change was also calculated using the same formula applied to the maximum rates. In addition, we examined how the place fields themselves changed across environments by quantifying the similarity between firing rate maps calculated as pixel-to-pixel $(3.5 \times$ $3.5 \mathrm{~cm}$ ) cross-correlations. Each firing rate map of the new environments was first scaled to match the map size of the familiar environments. The square arenas (new environments 2 and 3) were reshaped to cylinder form, and the slightly larger hexagon arena (new environment 1) was scaled down in size; the new plus maze (new environment 4) was the same size as the familiar maze and did not need adjustment of the firing rate maps. For each environment, the pixel-to-pixel correlations, and the spatial selectivity were calculated only if the overall mean firing rate was $>0.1 \mathrm{~Hz}$

\section{Statistical design}

In general, our analysis design compared the age group and environment interactions within each separate subregion using an ANOVA with repeated measures. In some special cases, we also compared the subregions within each separate age group using an ANOVA with repeated measures. To examine specifically the change in firing rates and place fields between environments, we compared the age groups using a $t$ test.

\section{Results}

\section{Description of the databases}

Before neurophysiological recordings, the spatial learning abilities of all 18 young and 17 aged rats were evaluated in the Morris water maze and indicated a deficit in spatial learning among the aged rats compared with the young [according to the analysis described in detail by Gallagher et al. (1993); learning index, young, $180 \pm 6$; aged, $\left.253 \pm 8 ; t_{(31)}=-6.9 ; p<0.001\right]$. Subsequently, we monitored hippocampal activity from these behaviorally characterized young and aged rats as they successively explored a familiar and a novel environment. From the CA1 subregion, we recorded 101 place cells in 17 young rats and 174 cells in 11 aged rats (see the locations of electrodes in Fig. 1). From the CA3 subregion we recorded 34 place cells in five young rats and 87 cells in eight aged rats. Those recordings included, on average, 4.0 cells simultaneously monitored, with a range from 1 to 10 cells. The data were collected from four novel environment setups, and initially we examined the data separately for each of these novel environments (shown in supplemental Table 1, available at www.jneurosci.org as supplemental material). Because the trends were similar within each, we pooled the novel environments together for analyses of the hippocampal subregions.

\section{Subregion differences in young animals}

We then separated the pooled data into cells located in either the CA1 or the CA3 subregion for analysis, using the firing patterns in
Table 1. A comparison of place cells from CA1 and CA3 subregions in young adult rats by Leutgeb et al. (2004) and our current experiment

\begin{tabular}{lll}
\hline & Leutgeb et al. (2004) & Current study \\
\hline Overall firing rate & CA1 $>C A 3^{* *}$ & $C A 1>C A 3^{*}$ \\
Maximum firing rate & CA1 $>C A 3^{* b}$ & $C A 1>C A 3^{\dagger}$ \\
Field size & CA1 $>C A 3^{* *}$ & $C A 1>C A 3^{* * a}$ \\
Sharpness & CA3 $>C A 1^{* *}$ & $C A 3>C A 1^{* b}$ \\
\hline
\end{tabular}

For means \pm SEM from the current experiment, see Figure 5. Statistical analyses for the current experiment used an ANOVA with repeated measures. ${ }^{*} p<0.05 ;{ }^{* *} p<0.01$; ${ }^{* * *} p<0.001$; ${ }^{\dagger}$ trend $p=0.13$. The sharpness of place fields was measured by sparsity in Leutgeb et al. (2004), whereas the current experiment measured sharpness by the information content (see Materials and Methods).

${ }^{a}$ Familiar environment only.

${ }^{b}$ Novel environment only.

familiar and novel environments as the within-subject repeated measure. Before comparing across age groups, we examined the firing patterns of cells recorded in the young rats for subregion differences. Differences between cells recorded in the CA1 and CA3 subregions in those rats were consistent with findings published recently. Table 1 compares our data with the results reported by Leutgeb et al. (2004), using the same Long-Evans rat strain. In both studies, cells in the CA3 subregion had lower firing rates and smaller, sharper place fields than cells in the CA1 subregion. These comparisons confirm consistent subregional differences in firing patterns across studies and strengthen the validity of the following comparison with aged rats.

\section{Aged CA3 place cells are hyperactive}

In the CA1 subregion, we found no difference in the mean overall or maximum firing rates between the age groups (age effects, $F_{(1,273)}<1.0, p>0.3$ ) (Fig. $5 A, B$ ). There was a trend in both groups toward higher overall firing rates in the novel environment compared with the familiar one (environment effect, $F_{(1,273)}=4.7, p=0.03$; age-by-environment interaction: $\left.F_{(1,273)}=1.2, p=0.28\right)$. There was also no difference in maximum firing rates across environments between young and aged rats (no age-by-environment interaction).

In contrast, CA3 cells in the aged animals had significantly higher mean overall and maximum firing rates than CA3 cells in the young animals (age effect, $F_{(1,119)}>14.3, p<0.001$ ) (see examples in Fig. 4 and means in Fig. 5A,B). Notably, whereas CA 3 cells in young rats had lower firing rates than CA1 cells (see Table 1), CA3 cells in aged rats had higher overall firing rates than CA1 cells (aged only subregion effect, $F_{(1,259)}=19.8, p<0.001$ ). Moreover, the CA3 cells of aged rats had higher overall firing rates in the novel environment than in the familiar one, whereas the cells of young rats decreased their overall firing rates in the novel environment (age-by-environment interaction, $F_{(1,119)}=4.4$, $p=0.04)$. These distinctions related to the environment were not seen in the maximum firing rates (Fig. $5 B$ ). Thus, the abnormally high firing rate of pyramidal cells in aged rats, which we had reported previously as a general feature of aged hippocampal neurons (Wilson et al., 2003, 2004), does not occur in the CA1 subregion but is selective to CA3 pyramidal cells.

Consistent with the lack of an age difference on firing rates in the CA1 subregion, the CA1 hippocampal cells of the young and aged rats had similarly sized place fields (number of pixels with firing $>1 \mathrm{~Hz}$; age effect, $F_{(1,269)}=0.1, p=0.8$ ) (Fig. $5 C$ ). In addition, in the novel environment, both groups had larger place fields than in the familiar environment (environment effect, $\left.F_{(1,269)}=35.5, p<0.001\right)$. In contrast, the place fields of CA3 cells were much larger in aged rats than in young rats (age effect, $F_{(1,118)}=35.1, p<0.001$ ) (Fig. $5 C$ ). In aged rats, the CA3 place 

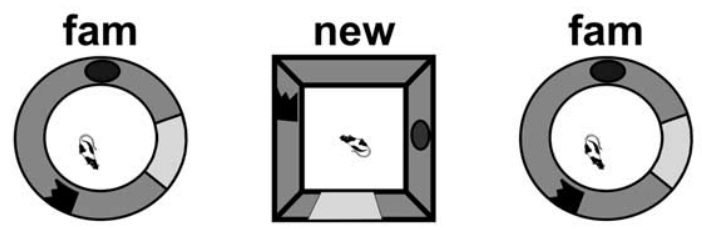

\section{A. Young CA3}
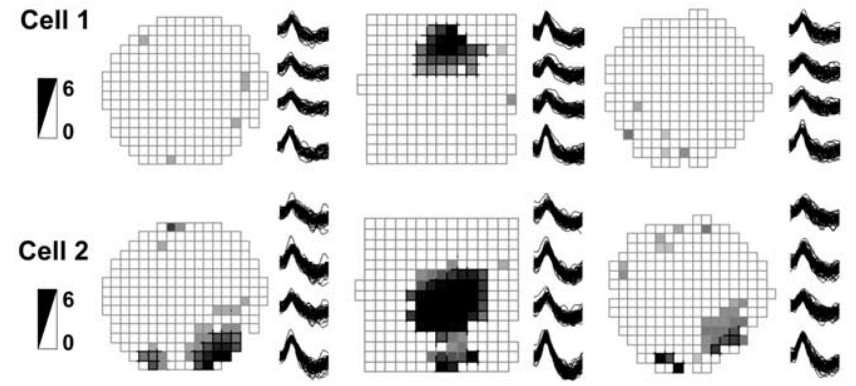

\section{B. Aged CA3}
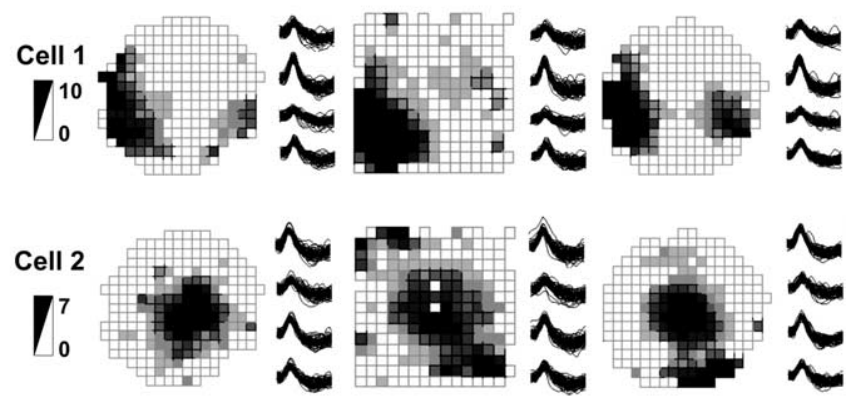

Figure 4. Examples of young $(\boldsymbol{A})$ and aged $(\boldsymbol{B})$ CA3 place fields. The top row depicts the experimental setup with the familiar (fam) environment and novel environment 2 . The recording sites, the place fields, the tetrode waveforms, and the firing rate scale (in spikes per second) of two simultaneously recorded cells from each rat are shown. Note that young CA3 cells created new spatial representations, and often some were active in only one environment (young cell 1). In contrast, the aged CA 3 cells used similar place field representations for both environments and scarcely changed their abnormally high firing rates. cc, Corpus callosum; PoDG, polymorphic region of the dentate gyrus; DG, dentate gyrus; D3V, dorsal third ventricle; dhc, dorsal hippocampal commissure.

fields were also larger in the novel environment than in the familiar one, whereas the CA3 place fields of young rats were equally small in both environments (age-by-environment interaction, $\left.F_{(1,118)}=5.8, p=0.02\right)$.

Are the higher firing rates and larger place fields of aged CA3 place cells secondary to changes in the specificity of spatial firing patterns? There was no effect of age on the overall spatial specificity of CA3 cells (age effect on spatial selectivity, $F_{(1,99)}=1.5$, $p=0.22$ ) (Fig. 5D). However, analysis of the significant interaction between age and environment $\left(F_{(1,108)}=9.2, p=0.003\right)$ indicated that the CA3 cells of young rats increased their selectivity in the novel environment (young environment effect, $F_{(1,20)}=$ 5.0, $p=0.04$ ) (Fig. 5D), whereas the CA3 cells of aged rats decreased selectivity in the novel environment compared with the
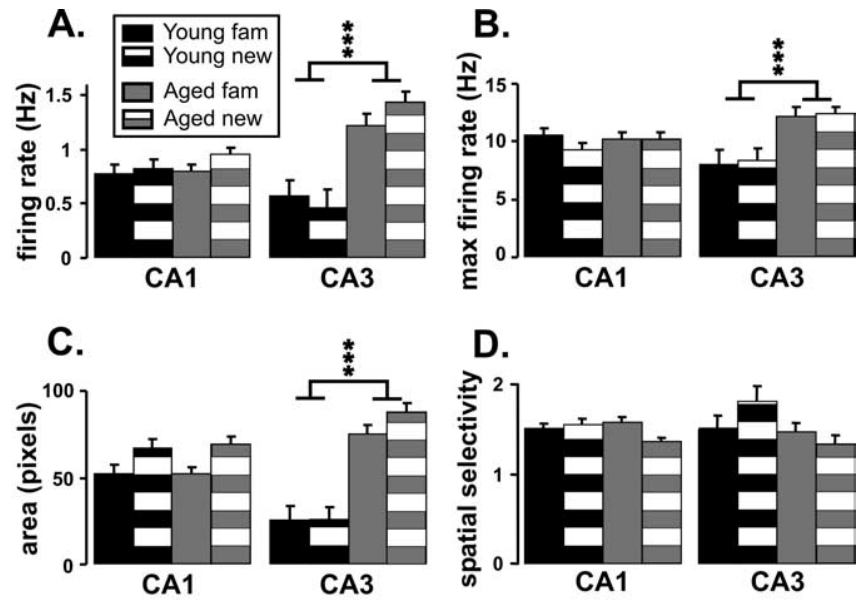

Figure 5. Aged CA3 cells have an abnormally high firing rate. The basic firing parameters of CA1 and CA3 place cells from young and aged rats are depicted in the familiar (fam) and novel environments. $\boldsymbol{A}$, Overall firing rate. $\boldsymbol{B}$, Maximum firing rate. $\boldsymbol{C}$, Area of high firing rate. $\boldsymbol{D}$, Spatial selectivity. Statistical significance, ${ }^{* * *} p<0.001$ for comparison of aged CA3 cells to young CA3 cells. Error bars represent SEM.

familiar (aged environment effect, $F_{(1,79)}=3.9, p=0.05$ ). Although the environment-selective differences in spatial specificity may reflect distinctions between young and aged rats in response to environmental change (see below), these analyses indicate that the age-associated abnormalities in CA3 firing rate and place field size are not secondary to an overall loss in spatial selectivity.

\section{Aged CA3 cells fail to rapidly encode changes in} the environment

We next examined how altering the environment affected the responses of CA1 and CA3 cells by analyzing three typical reflections of changes in their spatial representation: alterations in the mean overall firing rate, alterations in the maximum firing rate, and alterations in the location or shape of place fields. By each of these measures, in CA1, young and aged cells responded similarly, whereas in CA3, aged cells showed much less change in spatial representation in response to novelty than did young cells (see examples in Figs. 2-4).

First, we examined how well the mean overall firing rate for each neuron in the familiar environment predicted its firing rate in the novel environment (Fig. 6A,B). Similar to the report by Leutgeb et al. (2004), in young rats, the firing rates of CA1 cells in the two environments in our studies were correlated (Spearman's $\left.r_{(101)}=-0.42, p<0.001\right)$, whereas the firing rates of CA3 cells were not correlated across the two environments $\left(r_{(34)}=0.0 ; p=\right.$ $0.90)$. In contrast, in the aged rats the firing rates were correlated across the two environments for both CA1 cells and CA3 cells (CA1, $r_{(174)}=0.53, p<0.001$; CA3, $\left.r_{(87)}=0.73, p<0.001\right)$. Thus, in contrast to young CA3 place cells, which were active almost exclusively in one arena, aged CA3 place cells had similar levels of activity in both environments.

To quantify this further, we analyzed the extent of firing rate change. Raw firing rate change (accounting for direction and measuring the angle of the relationships in Fig. 6) did not show any differences between the aged groups for either subregion (CA1 age effect, $t_{(1,272)}=1.4, p=0.15$; CA3 age effect, $t_{(1,119)}=$ 1.0, $p=0.32$ ). This indicated that, for both groups, some cells increased and some cells decreased their firing rates.

The magnitude of changes in firing rate independent of direc- 

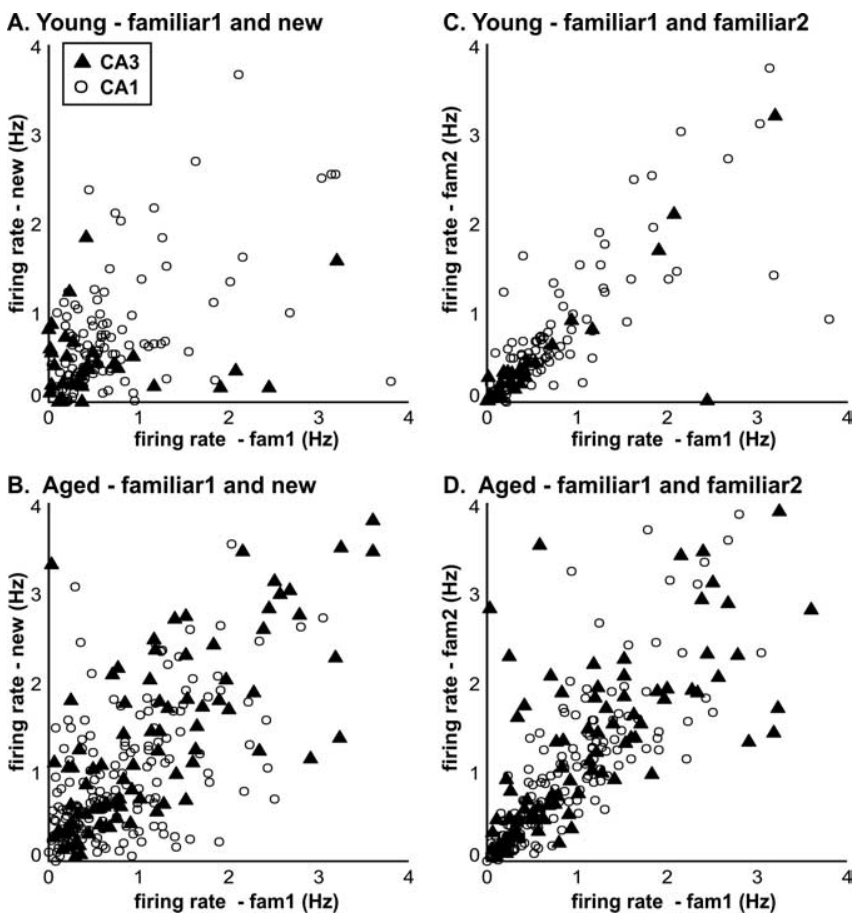

Figure 6. Comparison of firing rates of individual cells in the familiar and novel environments and in repeated trials in the familiar environment. $A$, Young cells in the familiar (trial 1 ) and novel environments. $\boldsymbol{B}$, Aged cells in the familiar (trial 1 ) and novel environments. $\boldsymbol{C}$, Young cells in the familiar1 (fam1) and familiar2 (fam2) trials. $\boldsymbol{D}$, Aged cells in the familiar1 and familiar2 trials. Note that firing rates were well correlated for all comparisons, except for those of young $C A 3$ cells between the familiar and new environments.

tion, indicative of the degrees of dispersion shown in Figure 6, showed that the CA3 cells of aged rats changed their firing patterns less than cells of young rats. The magnitude of change in CA1 cells was equivalent in young and aged rats (CA1 age effect, $\left.t_{(1,272)}=0.3, p=0.8\right)$ (Fig. $7 A$ ). In contrast, CA3 cells of young rats exhibited much greater change in firing rate than those of aged rats (CA3 age effect, $t_{(1,119)}=5.5, p<0.001$ ). We also compared the degree of firing rate change between subregions within each age group. In the young rats, CA3 cells had a much greater firing rate change than CAl cells (subregion effect, $t_{(1,133)}=-3.8, p<0.001$ ) (Fig. 7A), a finding consistent with the report by Leutgeb et al. (2004) for young rats. Remarkably, the pattern was reversed for the aged rats; their CA3 cells showed less firing rate change in response to the novel environment than CA1 cells (subregion effect, $t_{(1,258)}=2.1, p=0.03$ ) (Fig. $7 A$ ). Thus, aged CA3 cells failed to change their overall firing rates in response to a change in environment.

Second, a similar pattern was also evident in the maximum firing rates. For the young rats, maximum rates in the familiar environment predicted rates in the novel environment only in the case of CA1 cells (CA1, Spearman's $r_{(101)}=0.52, p<0.001$; CA3, $\left.r_{(34)}=-0.03, p=0.85\right)$, whereas in the aged rats, the maximum rates in both subregions were correlated in the two environments (CA1, $r_{(174)}=0.36, p<0.001$; CA3, $\left.r_{(87)}=0.40, p<0.001\right)$. Quantifying the magnitude of maximum firing rate changes showed that the age groups did not differ in the CA1 subregion $\left(t_{(1,272)}=-1.5, p>0.1\right)$, but the CA3 cells differed significantly as a function of age $\left(t_{(1,119)}=4.1, p=0.001\right)$ (Fig. $\left.7 B\right)$. The CA3 cells of young rats changed more than CA1 cells $\left(t_{(1,133)}=-3.9\right.$, $p<0.001)$, whereas the opposite trend was true for the aged rats $\left(t_{(1,258)}=1.8, p=0.07\right)$.
A.

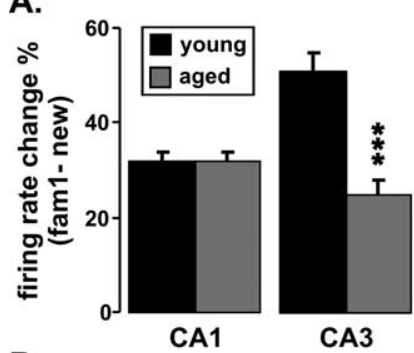

B.
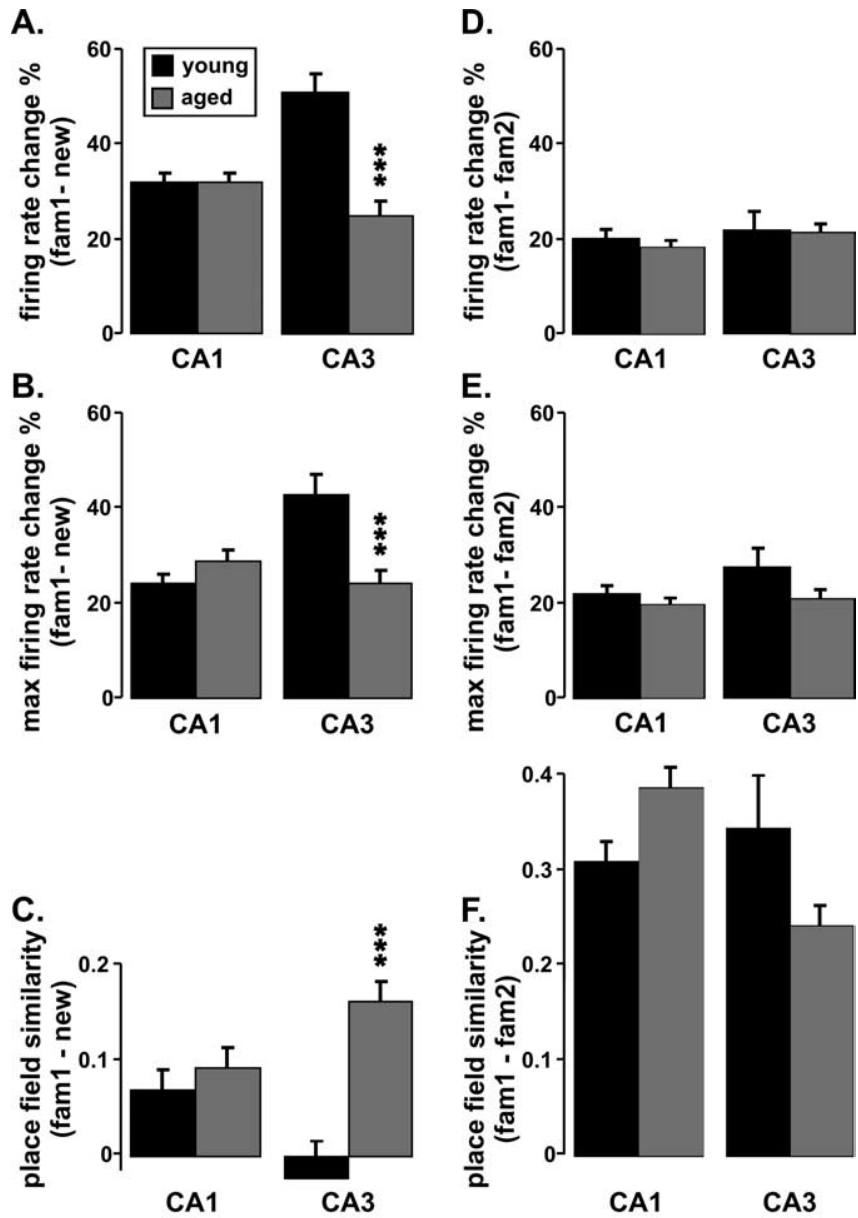

E.

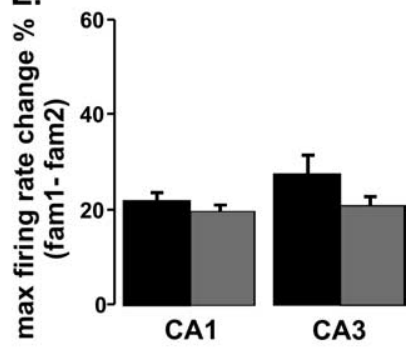

Figure 7. Aged CA3 cells fail to rapidly encode changes in the environment. In three measures of how much the place cells changed their firing patterns in response to the novel environment, the aged CA3 cells changed much less than young CA3 cells. In contrast, in the control comparison between repeated trials in the familiar environment, there were no differences between the age groups. $A$, Overall firing rate change between the familiar and new environments. $\boldsymbol{B}$, Maximum firing rate change between the familiar and new environments. $\boldsymbol{C}$, Place field correlation between the familiar and new environments. $\boldsymbol{D}$, Overall firing rate change between repeated trials in the familiar environment. $\boldsymbol{E}$, Maximum firing rate change between repeated trials in the familiar environment. $\boldsymbol{F}$, Place field correlation between repeated trials in the familiar environment. Statistical significance, ${ }^{* * *} p<0.001$ for comparison of aged CA3 cells to young CA3 cells. fam1, Familiar1; fam2, familiar2. Error bars represent SEM.

Third, we examined how the place fields changed across environments by quantifying the similarity between firing rate maps calculated as pixel-to-pixel $(3.5 \times 3.5 \mathrm{~cm})$ cross-correlations. This analysis yielded modest positive values for CA1 cells of aged as well as young rats, indicating an equivalent propensity to create a new spatial representation in the novel environment (CA1 age effect, $\left.t_{(1,267)}=-0.9, p=0.4\right)($ Fig. $7 C$ ). However, there was a striking age difference in the creation of new spatial representations in CA3 cells (CA3 age effect, $t_{(1,118)}=-4.7, p<0.001$ ) (Fig. $7 C)$. No discernible place field similarity across environments was evident in the CA3 cells of young rats, indicating that a distinct spatial representation was developed for the novel environment. In contrast, the substantially higher place field similarity for CA3 cells in aged rats indicates that new spatial representations were created much less often. Moreover, a comparison between subregions within each group revealed another sharp difference. As Leutgeb et al. (2004) reported, within young rats, CA3 cells showed substantially greater change in place fields than CA1 cells (young subregion effect, $t_{(1,131)}=3.0, p=0.003$ ). In striking 

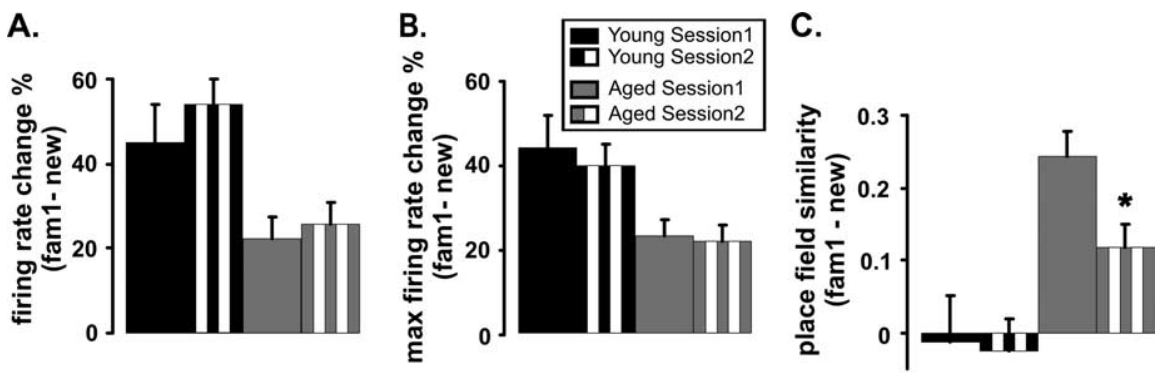

Figure 8. Changes in CA3 cells during the first and second sessions in the novel environment. Aged CA3 cells demonstrated less change than young CA3 cells during both sessions in the novel environment. Only CA3 cells are shown. $\boldsymbol{A}$, Firing rate change. $\boldsymbol{B}$, Maximum firing rate change. $C$, Place field similarity. Statistical significance, ${ }^{*} p<0.05$ for comparison within aged CA3 of the first and second sessions. fam1, Familiar1; fam2, familiar2. Error bars represent SEM.

contrast, within aged rats, CA3 cells showed substantially less change in place fields than the CA1 cells (aged subregion effect, $\left.t_{(1,254)}=-2.4, p=0.02\right)$.

Stable place fields between trials in the familiar environment As a control comparison to the change of environment, the rats were returned to the familiar environment immediately after the novel environment. Then, most place cells of both young and aged rats reestablished their original familiar environment representations (see examples in Figs. 2, 4). Firing rates in the initial familiar environment predicted firing rates in the second familiar environment for cells of both CA1 and CA3 subregions of both young and aged rats (Fig. 6C,D) (young CA1, $r_{(96)}=0.79, p<$ 0.001 ; young CA3, $r_{(30)}=0.72, p<0.001$; aged CA1, $r_{(172)}=0.88$, $p<0.001)$; aged CA $\left.3, r_{(84)}=0.72, p<0.001\right)$. Furthermore, cells from young and aged rats had equally low magnitudes of changes in both the overall and maximum firing rates of CA1 cells (Fig. $7 D, E)\left(t_{(1,264)}<1.1, p>0.3\right)$ and of CA3 cells $\left(t_{(1,112)}<1.6, p>\right.$ $0.1)$. The CA1 place fields of young rats were less similar than those of aged rats between the two trials in the familiar environment (Fig. $7 F)\left(t_{(1,258)}=-2.3, p=0.02\right)$, but CA3 place fields were equally similar $\left(t_{(1,105)}=1.6, p>0.1\right)$. Most importantly for the control comparison, the magnitude of firing rate and place field change between the trials was much greater for the familiarto-novel environment transition than for repeated trials in the familiar environment in cells of both subregions from both young and aged rats (effect of change: CA1, $F_{(1,264)}>12.3, p<$ 0.001 ; CA3, $\left.F_{(1,112)}>9.0, p<0.003\right)$. These results speak against a general effect on the aging hippocampus of changing trials (such as disorientation between trials) and suggest that it is the encoding of new information by the aged CA3 hippocampus, which is particularly impaired.

\section{CA3 cells in the second novel session}

It is possible that the CA3 cells of aged animals may require more exposure to the novel environment to distinguish it from a familiar one. To test this, we analyzed CA3 cells from those rats that had been exposed twice to novel environments 1 and 2 . All of the age effects seen in CA3 cells were present in both the first and second sessions (Fig. 8). The basic firing parameters of overall firing rate, maximum firing rate, and area of high firing rate were higher for CA3 cells of aged rats than for those of young rats in both sessions (age effect, $F_{(1,93)}>19.9, p<0.001$ ), and there were no effects of session or session-by-age interactions (session effect, $F_{(1,93)}<1.2, p>0.28$; session-by-age interaction: $F_{(1,93)}<2.7$, $p>0.1)$. Important with respect to learning, the place cells of the aged animals changed their overall and maximum firing rates as well as place fields less than those of the young animals in both sessions (age effect, $F_{(1,93)}>12.9, p<0.001$; session effect, $F_{(1,93)}<2.3, p>0.1$; session-by-age interaction: $F_{(1,93)}<1.6, p>0.2$ ) (Fig. 8). Within the aged rats, the CA3 cells did not show any increase in magnitude of firing rate change from the first to second session, but the place fields were less similar between the two environments in the second session than in the first (aged only session effect, $\left.t_{(1,66)}=2.4, p=0.02\right)$. These results suggest that the place fields of aged rats may require even more exposure to fully develop new representations [for additional discussion, see Wilson et al. (2004)]. However, the absence of any increase in firing rate change even with the second exposure points to the inability of aged CA3 cells to turn on and off as a critical contribution to poor information processing by the aging hippocampus.

\section{No differences across the CA3 transverse axis in young rats}

Because the majority of recordings in young animals were from $\mathrm{CA} 3 \mathrm{c}$, whereas the majority of recordings in young animals were from the CA3a, it is possible that age-related differences seen here may actually originate from differences in firing patterns between sub-subregions. To control for this, we compared the activity of cells from CA3a and CA3c (albeit with limited numbers) in supplementary Table 2 (available at www.jneurosci.org as supplemental material). In the young animals, the activity was similar along the CA3 transverse axis, indicating that differences between the groups arise from an age-related contribution.

\section{Analysis by ensembles yields the same results as analysis by cells}

Because the numbers of recorded cells differed among electrodes, using individual cells as the unit for assessments could potentially skew the results toward those characteristic of rats with a large number of recorded cells. To exclude this potential bias, we performed the same analyses based on ensembles of cells rather than individual cells. The ensemble values consisted of the average of all cells recorded simultaneously by one tetrode. Admittedly, this analysis method also contains a bias (toward rats with many recorded ensembles) but in a different way than the analysis based on cells. The results using both methods were similar, indicating that any bias in the analyses based on individual cells would be minimal (see supplemental Table 3 for details, available at www. jneurosci.org as supplemental material).

\section{Discussion}

The results presented here indicate that the hippocampal CA3 subregion may play a particularly important role in age-related deficits in cognition. Past analyses of hippocampal information processing in aged animals have focused either exclusively on cells of the CA1 subregion (Barnes et al., 1997; Shen et al., 1997; McEchron et al., 2001; Rosenzweig et al., 2003) or have combined the data obtained from the CA1 and CA3 subregions for analytical purposes (Tanila et al., 1997a; Oler and Markus, 2000; Wilson et al., 2003, 2004, 2005). In studies of aging that did analyze subregions separately (Mizumori et al., 1996; Mizumori and Kalyani, 1997), the experimental conditions for recordings were not suitable for detecting the distinctive features of CA1 and CA3 encoding in response to changes in the environment. 
In making this hippocampal subregion comparison, we found that the CA1 cells of aged rats had firing properties similar to those of the young adults: both groups had overall firing rates at similar values and made some adjustments in firing rates in response to a change in the environment. The CA3 cells of aged rats, in contrast, differed from young adults in two important ways: CA3 cells in the aged rats had abnormally high firing rates when compared with young rats, and they did not show a robust response to the novel environment, indicating a failure to distinguish change when new information was provided. Thus, an absence of rapid encoding of environment-specific features in the CA3 subregion could provide a basis for the consistent ageassociated behavioral impairment that is observed in spatial learning (Barnes and McNaughton, 1980; Gage et al., 1984; Gallagher and Burwell, 1989; Mizumori and Kalyani, 1997).

The dissociation between CA3 and CA1 responses strongly implies that the aging effects on hippocampal physiology are not secondary to any more general deficit, such as sensory, perceptual, motivational, or motor impairments. Recourse to such explanations would have to account for how a general deficit could selectively alter processing by cells in subregion CA3 but not CA1.

\section{Hyperactivity of aged CA3 cells}

In young rats, it has often been found that CA1 cells have higher firing rates than CA3 cells (Mizumori et al., 1996; Oler and Markus, 2000; Brazhnik et al., 2003; Leutgeb et al., 2004) (but see Lee et al., 2004a). The current data show that this pattern is reversed in aged rats; their CA3 cells had higher firing rates than their CA1 cells and higher firing rates than young CA3 cells. Why would aged CA3 cells have abnormally high firing rates? Three age-related changes in the hippocampal formation may pave the way for hyperactivity of principle neurons in the CA3 subregion, where the circuit includes recurrent excitation by CA3 collaterals.

First, in contrast to preserved number of pyramidal cells (Rapp and Gallagher, 1996), the number of hippocampal inhibitory interneurons or the intensity of glutamic acid decarboxylase (GAD) immunostaining is decreased in aging (Cadacio et al., 2003; Vela et al., 2003; Stanley and Shetty, 2004). Second, the degree of cholinergic modulation is attenuated (Chouinard et al., 1995; Sugaya et al., 1998; Nicolle et al., 1999). Both of those effects may be particularly influential in the CA3 stratum radiatum, in which the CA3 recurrent collaterals terminate (Freund and Buzsaki, 1996). Specifically, Stanley and Shetty (2004) noted a pronounced decrease in GAD-67 immunostaining in the stratum radiatum of aged brains, and Hasselmo et al. (1995) have shown, through slice recordings from activated recurrent collaterals, that reduced cholinergic input releases the CA3 autoassociation fibers from inhibition.

Third, aging is accompanied by a substantial reduction in the synaptic innervation from entorhinal cortex layer II neurons into the dentate gyrus and the CA3 subregions (Barnes and McNaughton, 1980; Geinisman et al., 1992; Smith et al., 2000). At the same time, markers for the connectional zone occupied by the CA3 recurrent excitatory synapses remain unaffected by aging (Rapp et al., 1999; Smith et al., 2000). Spiking activity in the dentate gyrus activates hilar interneurons, which, in turn, suppress CA3 pyramidal cells (Bragin et al., 1995). Removal of the entorhinal cortex results in an absence of such dentate spikes and a severalfold increase in CA3-CA1 sharp-wave bursts generated by CA3 recurrent collaterals (Bragin et al., 1995). A similar disinhibitory effect may arise from the partial reduction of entorhinal innervation in aging.

Thus, some combination of reduced interneuron function in

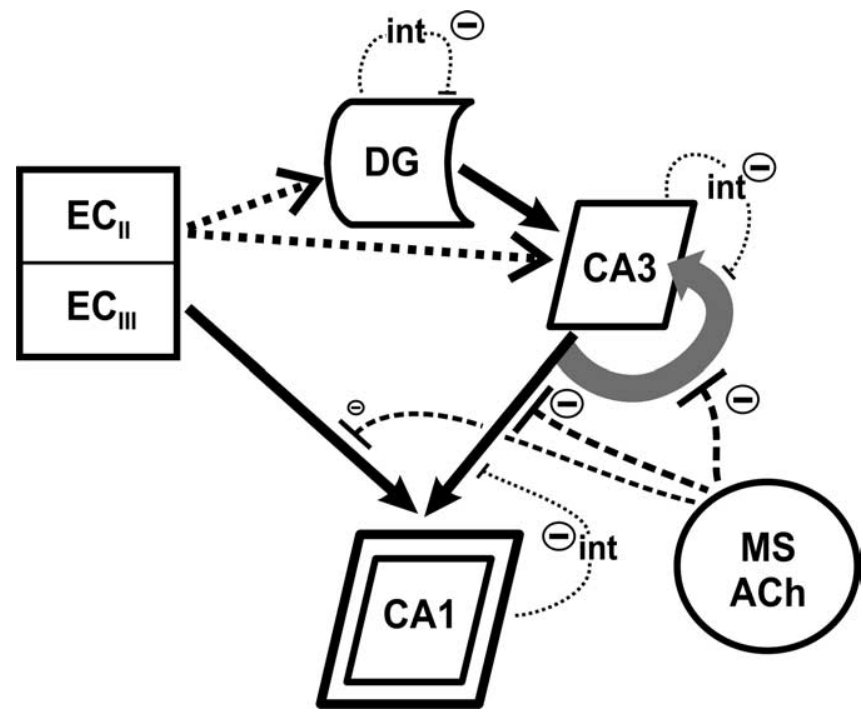

Figure 9. Age-related changes to the hippocampal circuit. Dashed lines indicate a decrease with aging. Solid arrows remain intact. With aging, the entorhinal cortex provides less input to dentate gyrus and $C A 3$, the medial septum provides less cholinergic modulation, interneuron activity is decreased, and the CA1 hippocampus is less excitable (depicted with a doubly insulated box). These changes may increase the activity of $C A 3$ recurrent collaterals (in gray). EC, Entorhinal cortex; DG, dentate gyrus; int, interneurons; MS, medial septum; ACh, acetylcholine.

the stratum radiatum, decreased cholinergic modulation from basal forebrain innervation, and diminished input from entorhinal cortex to the dentate gyrus could underlie hyperactivity of CA3 neurons in an aged hippocampus. We have incorporated these age-associated changes into a model of hippocampal information processing in which the CA3 autoassociative network becomes disinhibited, such that pattern completion dominates function in this subregion of the hippocampus (Fig. 9).

\section{Failure of aged CA3 cells to rapidly encode new information} Recent evidence (for review, see Guzowski et al., 2004) has provided empirical support for theoretical considerations (Marr, 1971; McNaughton and Morris, 1987; O’Reilly and McClelland, 1994; Treves and Rolls, 1994; Redish, 1999) on the role of each hippocampal subregion in information processing. Those data support a model in which the CA3 subregion is critical for rapid encoding of new information, whereas the CA1 subregion serves for comparing outputs from the entorhinal cortex and the CA3 subregion (Lee et al., 2004a; Leutgeb et al., 2004). Furthermore, when the environment change is minor, the CA3 subregion employs autoassociation via the recurrent collaterals to make the representations more similar (pattern complete), whereas, without this extensive recurrent system, CA1 shows less overlap in its spatial representations (Lee et al., 2004b; Vazdarjanova and Guzowski, 2004). When the difference between two successively experienced environments is great, CA3 cells produce very different spatial firing patterns, whereas CA1 cells maintain more similar place fields (Leutgeb et al., 2004; Vazdarjanova and Guzowski, 2004). The changes in environment used in our experiments could be considered great, such that pattern separation in CA3 would be expected.

In our data, the CA3 cells of young rats showed evidence of pattern separation, whereas those of aged rats did not. Why would the aged CA3 fail to rapidly encode new information? First, the dentate gyrus, hypothesized to be critical for pattern separation (Marr, 1971; McNaughton and Morris, 1987; O'Reilly and McClelland, 1994; Treves and Rolls, 1994; Redish et al., 1998; 
Redish, 1999), shows less activation in both aged monkeys and aged rats compared with young animals (Small et al., 2004).

Second, age-related decreases in entorhinal cortical contacts and in cholinergic modulation, which, as described previously, likely increase the firing rate of CA3 cells, are also likely to decrease the amount of external information arriving in CA3 while increasing the emphasis in CA3 on already stored patterns. Supporting this, in young rats, inactivation (Lassalle et al., 2000) and lesion (Lee and Kesner, 2004) of the mossy fiber input to CA3 produce deficits in learning new information but not in retrieval of stored information, as predicted by theoretical considerations (Treves and Rolls, 1992).

Third, synaptic plasticity, as measured by long-term potentiation, is generally weakened in the hippocampus of aged rats (Barnes, 1994; Foster, 1999; Wu et al., 2002), although LTP of the mossy fibers has not been tested. These adjustments in the circuit would encourage maintenance of the same information in the CA3 network over encoding of new information (see model in Fig. 9), and it would be interesting to test whether aged animals would actually outperform young animals on a pattern completion task, such as that used by Nakazawa et al. (2002). Furthermore, these considerations raise the question of whether the failure of aged CA3 to rapidly encode new information arises from too much pattern completion by the CA3 or from too little pattern separation by the dentate gyrus.

Why do the CA1 cells not show age-related firing abnormalities? In young rats, the CA1 firing pattern can arise independently of CA3 activity (Lee et al., 2004b; Leutgeb et al., 2004), and CA1 place cells have been shown to encode environment-specific information despite a lesion or suppression of CA3 (Mizumori et al., 1989; Brun et al., 2002). In aged rats, the preserved projection from entorhinal layer III to CA1 (Smith et al., 2000) may sufficiently support the independence of CA1 cells so that less rigidity is seen in their response to new information than in CA3 cells (current data), but one could predict that, under conditions in which the firing of place cells is more dependent on information stored in the hippocampus, aged CA1 cells would also exhibit rigid characteristics.

\section{Conclusions}

The results of the present study indicate a pronounced hyperactivity and a failure to rapidly encode new information afflicting the CA3 pyramidal neurons. Aged CA1 neurons, in contrast, showed neither characteristic under conditions of the current experiments and were thus similar to young CA1 neurons. These results suggest that the CA3 hippocampal subregion, which has received relatively little attention in aging studies thus far, may play a key role in the age-related changes that underlie spatial memory impairment.

\section{References}

Barnes CA (1979) Memory deficits associated with senescence: a neurophysiological and behavioral study in the rat. J Comp Physiol Psychol 93:74-104.

Barnes CA (1994) Normal aging: regionally specific changes in hippocampal synaptic transmission. Trends Neurosci 17:13-18.

Barnes CA, McNaughton BL (1980) Physiological compensation for loss of afferent synapses in rat hippocampal granule cells during senescence. J Physiol (Lond) 309:473-485.

Barnes CA, Suster MS, Shen J, McNaughton BL (1997) Multistability of cognitive maps in the hippocampus of old rats. Nature 388:272-275.

Bostock E, Muller RU, Kubie JL (1991) Experience-dependent modifications of hippocampal place cell firing. Hippocampus 1:193-205.

Bragin A, Jando G, Nadasdy Z, van Landeghem M, Buzsaki G (1995) Den- tate EEG spikes and associated interneuronal population bursts in the hippocampal hilar region of the rat. J Neurophysiol 73:1691-1705.

Brazhnik ES, Muller RU, Fox SE (2003) Muscarinic blockade slows and degrades the location-specific firing of hippocampal pyramidal cells. J Neurosci 23:611-621.

Brun VH, Otnass MK, Molden S, Steffenach HA, Witter MP, Moser MB, Moser EI (2002) Place cells and place recognition maintained by direct entorhinal-hippocampal circuitry. Science 296:2243-2246.

Cadacio CL, Milner TA, Gallagher M, Pierce JP, Cadiacio CL (2003) Hilar neuropeptide $\mathrm{Y}$ interneuron loss in the aged rat hippocampal formation. Exp Neurol 183:147-158.

Chouinard ML, Gallagher M, Yasuda RP, Wolfe BB, McKinney M (1995) Hippocampal muscarinic receptor function in spatial learning-impaired aged rats. Neurobiol Aging 16:955-963.

Chrobak JJ, Buzsaki G (1998) Operational dynamics in the hippocampalentorhinal axis. Neurosci Biobehav Rev 22:303-310.

Foster TC (1999) Involvement of hippocampal synaptic plasticity in agerelated memory decline. Brain Res Brain Res Rev 30:236-249.

Freund TF, Buzsaki G (1996) Interneurons of the hippocampus. Hippocampus 6:347-470.

Gage FH, Dunnett SB, Bjorklund A (1984) Spatial learning and motor deficits in aged rats. Neurobiol Aging 5:43-48.

Gallagher M, Burwell RD (1989) Relationship of age-related decline across several behavioral domains. Neurobiol Aging 10:691-708.

Gallagher M, Burwell R, Burchinal M (1993) Severity of spatial learning impairment in aging: development of a learning index for performance in the Morris water maze. Behav Neurosci 107:618-626.

Geinisman Y, de Toledo-Morrell L, Morrell F, Persina IS, Rossi M (1992) Age-related loss of axospinous synapses formed by two afferent systems in the rat dentate gyrus as revealed by the unbiased stereological dissector technique. Hippocampus 2:437-444.

Guzowski JF, Knierim JJ, Moser EI (2004) Ensemble dynamics of hippocampal regions CA3 and CA1. Neuron 44:581-584.

Hasselmo ME, Schnell E, Barkai E (1995) Dynamics of learning and recall at excitatory recurrent synapses and cholinergic modulation in rat hippocampal region CA3. J Neurosci 15:5249-5262.

Ikonen S, McMahan R, Gallagher M, Eichenbaum H, Tanila H (2002) Cholinergic system regulation of spatial representation by the hippocampus. Hippocampus 12:386-397.

Jung MW, McNaughton BL (1993) Spatial selectivity of unit activity in the hippocampal granular layer. Hippocampus 3:165-182.

Lassalle JM, Bataille T, Halley H (2000) Reversible inactivation of the hippocampal mossy fiber synapses in mice impairs spatial learning, but neither consolidation nor memory retrieval, in the Morris navigation task. Neurobiol Learn Mem 73:243-257.

Lee I, Kesner RP (2004) Encoding versus retrieval of spatial memory: double dissociation between the dentate gyrus and the perforant path inputs into CA3 in the dorsal hippocampus. Hippocampus 14:66-76.

Lee I, Rao G, Knierim JJ (2004a) A double dissociation between hippocampal subfields: differential time course of CA3 and CA1 place cells for processing changed environments. Neuron 42:803-815.

Lee I, Yoganarasimha D, Rao G, Knierim JJ (2004b) Comparison of population coherence of place cells in hippocampal subfields CA1 and CA3. Nature 430:456-459.

Leutgeb S, Leutgeb JK, Treves A, Moser MB, Moser EI (2004) Distinct ensemble codes in hippocampal areas CA3 and CA1. Science 305:1295-1298.

Markus EJ, Barnes CA, McNaughton BL, Gladden VL, Skaggs WE (1994) Spatial information content and reliability of hippocampal CA1 neurons: effects of visual input. Hippocampus 4:410-421.

Marr D (1971) Simple memory: a theory for archicortex. Philos Trans R Soc Lond B Biol Sci 262:23-81.

McEchron MD, Weible AP, Disterhoft JF (2001) Aging and learningspecific changes in single-neuron activity in CA1 hippocampus during rabbit trace eyeblink conditioning. J Neurophysiol 86:1839-1857.

McNaughton BL, Morris RGM (1987) Hippocampal synaptic enhancement and information storage within a distributed memory system. Trends Neurosci 10:408-415.

Mizumori SJ, Kalyani A (1997) Age and experience-dependent representational reorganization during spatial learning. Neurobiol Aging 18:651-659.

Mizumori SJ, McNaughton BL, Barnes CA, Fox KB (1989) Preserved spatial 
coding in hippocampal CA1 pyramidal cells during reversible suppression of CA3c output: evidence for pattern completion in hippocampus. J Neurosci 9:3915-3928.

Mizumori SJ, Lavoie AM, Kalyani A (1996) Redistribution of spatial representation in the hippocampus of aged rats performing a spatial memory task. Behav Neurosci 110:1006-1016.

Morris RG, Garrud P, Rawlins JN, O'Keefe J (1982) Place navigation impaired in rats with hippocampal lesions. Nature 297:681-683.

Nakazawa K, Quirk MC, Chitwood RA, Watanabe M, Yeckel MF, Sun LD, Kato A, Carr CA, Johnston D, Wilson MA, Tonegawa S (2002) Requirement for hippocampal CA3 NMDA receptors in associative memory recall. Science 297:211-218.

Nakazawa K, Sun LD, Quirk MC, Rondi-Reig L, Wilson MA, Tonegawa S (2003) Hippocampal CA3 NMDA receptors are crucial for memory acquisition of one-time experience. Neuron 38:305-315.

Nicolle MM, Colombo PJ, Gallagher M, McKinney M (1999) Metabotropic glutamate receptor-mediated hippocampal phosphoinositide turnover is blunted in spatial learning-impaired aged rats. J Neurosci 19:9604-9610.

Oler JA, Markus EJ (2000) Age-related deficits in the ability to encode contextual change: a place cell analysis. Hippocampus 10:338-350.

O’Reilly RC, McClelland JL (1994) Hippocampal conjunctive encoding, storage, and recall: avoiding a trade-off. Hippocampus 4:661-682.

Paxinos G, Watson C (1998) The rat brain in stereotaxic coordinates. San Diego: Academic.

Rapp PR, Gallagher M (1996) Preserved neuron number in the hippocampus of aged rats with spatial learning deficits. Proc Natl Acad Sci USA 93:9926-9930.

Rapp PR, Stack EC, Gallagher M (1999) Morphometric studies of the aged hippocampus. I. Volumetric analysis in behaviorally characterized rats. J Comp Neurol 403:459-470.

Redish AD (1999) Beyond the cognitive map: from place cells to episodic memory. Cambridge, MA: MIT.

Redish AD, McNaughton BL, Barnes CA (1998) Reconciling Barnes et al. (1997) and Tanila et al. (1997a,b). Hippocampus 8:438-443.

Rosenzweig ES, Barnes CA (2003) Impact of aging on hippocampal function: plasticity, network dynamics, and cognition. Prog Neurobiol 69:143-179.

Rosenzweig ES, Redish AD, McNaughton BL, Barnes CA (2003) Hippocampal map realignment and spatial learning. Nat Neurosci 6:609-615.

Save E, Nerad L, Poucet B (2000) Contribution of multiple sensory information to place field stability in hippocampal place cells. Hippocampus 10:64-76.

Shen J, Barnes CA, McNaughton BL, Skaggs WE, Weaver KL (1997) The effect of aging on experience-dependent plasticity of hippocampal place cells. J Neurosci 17:6769-6782.

Skaggs WE, McNaughton BL, Gothard KM, Markus, EJ (1993) An information theoretic approach to deciphering the hippocampal code. In: Ad- vances in neural information processing systems (Hanson SJ, Cowan JD, Giles CL, eds), pp 1030-1037. San Mateo, CA: Morgan Kaufman.

Small SA, Chawla MK, Buonocore M, Rapp PR, Barnes CA (2004) Imaging correlates of brain function in monkeys and rats isolates a hippocampal subregion differentially vulnerable to aging. Proc Natl Acad Sci USA 101:7181-7186.

Smith TD, Adams MM, Gallagher M, Morrison JH, Rapp PR (2000) Circuit-specific alterations in hippocampal synaptophysin immunoreactivity predict spatial learning impairment in aged rats. J Neurosci 20:6587-6593.

Stanley DP, Shetty AK (2004) Aging in the rat hippocampus is associated with widespread reductions in the number of glutamate decarboxylase-67 positive interneurons but not interneuron degeneration. J Neurochem $89: 204-216$.

Sugaya K, Greene R, Personett D, Robbins M, Kent C, Bryan D, Skiba E, Gallagher M, McKinney M (1998) Septo-hippocampal cholinergic and neurotrophin markers in age-induced cognitive decline. Neurobiol Aging 19:351-361.

Tanila H, Shapiro M, Gallagher M, Eichenbaum H (1997a) Brain aging: changes in the nature of information coding by the hippocampus. J Neurosci 17:5155-5166.

Tanila H, Sipila P, Shapiro M, Eichenbaum H (1997b) Brain aging: impaired coding of novel environmental cues. J Neurosci 17:5167-5174.

Treves A, Rolls ET (1992) Computational constraints suggest the need for two distinct input systems to the hippocampal CA3 network. Hippocampus 2:189-199.

Treves A, Rolls ET (1994) Computational analysis of the role of the hippocampus in memory. Hippocampus 4:374-391.

Vazdarjanova A, Guzowski JF (2004) Differences in hippocampal neuronal population responses to modifications of an environmental context: evidence for distinct, yet complementary, functions of CA3 and CA1 ensembles. J Neurosci 24:6489-6496.

Vela J, Gutierrez A, Vitorica J, Ruano D (2003) Rat hippocampal GABAergic molecular markers are differentially affected by ageing. J Neurochem 85:368-377.

Wilson IA, Ikonen S, McMahan RW, Gallagher M, Eichenbaum H, Tanila H (2003) Place cell rigidity correlates with impaired spatial learning in aged rats. Neurobiol Aging 24:297-305.

Wilson IA, Ikonen S, Gureviciene I, McMahan RW, Gallagher M, Eichenbaum H, Tanila H (2004) Cognitive aging and the hippocampus: how old rats represent new environments. J Neurosci 24:3870-3878.

Wilson IA, Ikonen S, Gurevicius K, McMahan RW, Gallagher M, Eichenbaum H, Tanila H (2005) Place cells of aged rats in two visually identical compartments. Neurobiol Aging 26:1099-1106.

Wu WW, Oh MM, Disterhoft JF (2002) Age-related biophysical alterations of hippocampal pyramidal neurons: implications for learning and memory. Ageing Res Rev 1:181-207. 